\title{
Noções categorias no Modelo dos Campos Semânticos a partir de vieses entre triângulo de Pascal, números tetraédricos e números figurados triangulares
}

\section{Notions categories in the Semantic Fields Model from biases between Pascal triangles, tetrahedral numbers and triangular figurate numbers}

\author{
Rodolfo Chaves ${ }^{1}$ \\ Instituto Federal do Espirito Santo
}

Filyppe Neves de Andrade ${ }^{2}$

Instituto Federal do Espirito Santo

Tiago Magno de Souza Dutra ${ }^{3}$

Instituto Federal do Espírito Santo

\begin{abstract}
Resumo
No presente artigo apresenta-se e discute-se algumas ideias e noções categoriais, relativas à produção de significados, como procedimento a partir do Modelo dos Campos Semânticos, tomando resíduos de enunciação produzidos em uma reunião do Projeto "Pitágoras: em (e além do) teorema", desenvolvido por integrantes do Grupo de Estudos e Pesquisas em Modelo dos Campos Semânticos e Educação Matemática, ao tratarem da generalização de números tetraédricos, como uma categoria de números figurados, objeto de estudo da escola pitagórica, que produziu fascínio em diversos matemáticos ao longo da história da humanidade. O objetivo principal é apresentar essas ideias básicas do Modelo epistemológico em questão e aplicá-las nos resíduos de enunciação expostos, nas formas de diálogos, tabelas, figuras e outros textos utilizados, efetuando leituras acerca da produção de significados para o problema proposto.
\end{abstract}

Palavras-chave: Educação Matemática; Noções categoriais; Modelo dos Campos Semânticos; Números tetraédricos.

\begin{abstract}
In this article presentes and discusses some categorical ideas and notions, related to the production of meanings, as a procedure based on the Model of the Semantic Fields, taking enunciation residues produced in a meeting of the Project "Pitágoras: in (and beyond) the theorem", developed by members of the Group of Studies and Research in Model of the Semantic Fields and Mathematical Education, when dealing with the generalization of tetrahedral
\end{abstract}

${ }^{1}$ Doutor em Educação Matemática pela Universidade Estadual Paulista Júlio de Mesquita Filho (Unesp) - Rio
Claro e Pós-doutorado pela Universidade Federal de Santa Maria (UFSM) - RS. Professor titular do Instituto
Federal do Espírito Santo (Ifes), Vitória, ES, Brasil. Rua Jurandir Ferreira, 13, apt ${ }^{\circ}$ 4, Barra do Jucu, Vila Velha,
ES, Brasil, CEP 29.125-065. ORCID iD: https://orcid.org/0000-0002-6882-8483. Lattes:
httt://lattes.cnpq.br/3213154166347387. E-mail: rodolfochaves20@gmail.com.
2 Licenciado em Matemática pelo Instituto Federal do Espírito Santo (Ifes). Pesquisador júnior do Grupo de
Estudos e Pesquisas em Modelo dos Campos Semânticos e Educação Matemática (Gepemem), Vitória, ES, Brasil.
Rua Evaristo Canal, no 82 , bairro Universal, Viana, ES, Brasil, CEP: 29.134-513. ORCID iD:
https://orcid.org/0000-0002-4518-3678. Lattes: http://lattes.cnpq.br/1676275738815668. E-mail: filyppeneves@gmail.com.

${ }^{3}$ Mestre em Educação em Ciências e Matemática pelo Instituto Federal do Espírito Santo (Ifes). Professor de Educação Básica da Escola Estadual de Ensino Fundamental e Médio Antônio José Peixoto. (EEEFM Antônio José Peixoto - Sedu), Serra, ES, Brasil. Rua todos os Santos casa 01, quadra-128, Bairro das Laranjeiras, Serra, ES, Brasil, CEP: 29175-569. ORCID iD: http://orcid.org/0000-0002-70671331. Lattes: http://lattes.cnpq.br/4649641665691397.E-mail: tiagomagnodesouzadutra@hotmail.com. 
numbers, as a category of figurative numbers, object of study of the Pythagorean school, which has produced fascination among several mathematicians throughout the history of mankind. The main objective is to presente these basic ideas of the epistemological model in question and to apply them in exposed enunciation residues, in the forms of dialogues, tables, figures and other texts used making readings about the production of meanings for the proposed problem.

Keywords: Mathematics Education; Notions categories; Semantic Fields Model; Tetrahedral numbers.

\section{Introdução}

Neste artigo apresentamos e discutimos algumas ideias e noções categoriais, relativas à produção de significados, como procedimento a partir do Modelo dos Campos Semânticos (MCS), tomando resíduos de enunciação produzidos em uma reunião do Projeto "Pitágoras: em (e além do) teorema" - cadastrado junto à diretoria de pesquisa do Instituto Federal do Espírito Santo (Ifes), campus Vitória (PJ00004234, de setembro de 2017) -, desenvolvido por integrantes do Grupo de Estudos e Pesquisas em Modelo dos Campos Semânticos e Educação Matemática (Gepemem), ao tratarem da generalização de números tetraédricos, como uma categoria de números figurados, objeto de estudo da escola pitagórica.

Nosso objetivo principal é apresentar ideias básicas do Modelo epistemológico MCS e aplicá-las nos resíduos de enunciação apresentados, nas formas de diálogos, tabelas, figuras e outros textos utilizados, efetuando leituras acerca da produção de significados para o problema proposto, fruto de uma situação ocorrida em uma reunião de estudo do Projeto "Pitágoras: em (e além do) teorema", envolvendo alunos do curso de licenciatura em Matemática (Limat) e do Programa de Pós-Graduação em Educação em Ciências e Matemática (Educimat) ao tratarem da generalização de números tetraédricos.

Para tal, partimos da premissa de que algumas inquietações são pertinentes àqueles que objetivam transformar os quadros vigentes do ensino de Matemática. Perguntas como, "o que leva o aluno a 'errar'?”, “nos fizemos entender nesta explicação?”, “o que o aluno quis dizer com essa forma de operar?" etc., permeiam o cotidiano de grande parte de educadores. Mas o que podemos fazer para obtermos respostas a tais questões?

Primeiramente, tomamos como condição sine qua non a importância de "ler o aluno", "saber onde ele está", "procurar compreender de onde ele fala e porquê fala". Tal condição é fruto da busca por resposta às questões apresentadas no parágrafo antecedente, mas também como base do modelo epistemológico denominado Modelo dos Campos Semânticos - 
designado por MCS -, que tomamos como alicerce teórico em nossas pesquisas e ações como docentes.

Em segundo lugar, surgem outros questionamentos quando adotamos essa condição. Como ler o aluno? Como saber o que o leva a agir daquela forma? Para isso o elaborador do MCS, Prof. Dr. Romulo Campos Lins (1955-2017), defendia que é preciso falar. Colocar o aluno para falar a respeito do objeto em debate é o primeiro passo. E depois que ele fala, o que fazer? Bom, a tal respeito é o que pretendemos acenar, explícita ou implicitamente, ao longo do trabalho que desenvolvemos, apresentando aqui uma situação de estudo, envolvendo os atores do processo (dois licenciandos em Matemática, um professor da Prefeitura Municipal de Serra - ES, mestre em Educação em Ciências e Matemática e um professor - Limat e Educimat) em diálogos estabelecidos ao examinarem padrões contidos em uma sequência de números tratada na Aritmética pitagórica.

\section{Alguns sustentáculos teóricos}

Com o propósito de partirmos de algumas ancoragens históricas lembramos que os pitagóricos defendiam que "[...] todas as coisas são números [...]" (PICKOVER, 2009, p. 44) e que, por isso, no pitagorismo “[...] os números eram como deuses, puros e livres do mundo material" (PICKOVER, 2009, p. 44).

Para eles os números têm vida e por isso devotavam-se aos inteiros positivos - de $1 \mathrm{a}$ 10 - como uma forma de politeísmo. Nesse sentido, o Universo poderia ser entendido como uma escala musical, onde o número 1 (um) é tido como a essência da vida, o princípio criador. (DUTRA; CHAVES, 2020, p. 37).

Para os pitagóricos a unidade era o elemento criador de tudo:

Dentro da concepção de Pitágoras a unidade, isto é, a mônada era o elemento criador de tudo [...] Pitágoras chamava Um ao primeiro concerto de harmônios, o Fogo Viril, que tudo trespassa, o Espírito que se move por si mesmo, o Indivisível, e o grande Não-Manifestado, cujos mundos efêmeros revelam o pensamento criador, o Universo, o Eterno, o Imutável, o culto sob as coisas múltiplas e transitórias, que passam e mudam.” E. Schuré - "Os Grande Iniciados”, vol. II, pág. 162. (TAHAN, 1972 [1965], p. 35-36, ipsis litteris - destaques do autor). 
Também Roque (2014 [2012]) destaca que os números, na filosofia pitagórica, advêm do $u m$, princípio criador:

Todos os números, ou seres, teriam evoluído a partir do Um. Os números divididos em tipos associados a diferentes tipos de coisas. Para cada tipo, havia um primeiro, ou menor número, considerando sua 'raiz'. As relações entre os números não representavam, portanto, uma cadeia linear na qual todas as relações internas eram semelhantes. Cada arranjo designava uma ordem distinta, com ligações próprias. Daí o papel dos números figurados na matemática pitagórica. Esses números eram, de fato, figuras formadas por pontos, como as que encontramos em um dado. Não é uma cifra, como 3, que serve de representação pictórica para um número, mas a delimitação de uma área constituída de pontos, como uma constelação. (ROQUE, 2014 [2012], p. 105, destaques do autor).

Outras fontes consultadas trazem a ideia de que, para os pitagóricos o universo como um todo, bem como a respectiva harmonia podem ser reduzidas a números e portanto, ser natural que os estudassem ao pormenor.

Eles utilizavam muitas vezes representações figuradas dos números, dispondo pequenas pedras de formas diferentes, geralmente em figuras geométricas. Isto permitiu-lhes várias análises a respeito certas propriedades dos números, conseguindo outros, a partir dos anteriores, aplicando a regra que tinha a sequência com que estavam trabalhando. (MARQUES, 2011).

É possível que o interesse dos pitagóricos pela representação figurada ou poligonal de alguns números advenha do fato de, na época

[...] se contava através do uso de pedrinhas ou marcas de pontos na areia [...] as ideias relacionadas aos números figurados "resultam de arranjos com pontos ou pedrinhas de maneira a formar figuras geométricas" (DOMINGUES, 2009, p. 28, destaques do autor).

No tratamento de sequências de números figurados, também pautamo-nos em Deza e Deza (2012) com o propósito de discutirmos e procurarmos produzir conhecimento a respeito da sequência de números tetraédricos, que se configuram como uma categoria dos números figurados e, mesmo não sendo objetos centrais da Matemática, ao longo da história da humanidade, foram estudados por muitos matemáticos. Segundo Deza e Deza (2012), dedicaram-se ao estudo dos números figurados, nada mais, nada menos que: Pitágoras de Samos, Arquimedes, Hípsicles de Alexandria, Lúcio Méstrio Plutarco de Queroneia, Nicômaco 
de Gerasa, Téon de Esmirna, Diofanto de Alexandria, Leonardo Fibonacci, Michel Stifel, Girolamo Cardano, Bachet de Méziriac, René Descartes, Pierre de Fermat, John Pell, Blaise Pascal, Leonhard Eüler, Joseph-Louis Lagrange, Andrien-Marie Legendre, Carl Friedrich Gauss, Augustin-Louis Cauchy, Carl Gustav Jacob Jacobi, Wacław Sierpiński, Barnes Wallis e George Pólya. Ressaltamos que, no Brasil, Júlio Cezar de Mello e Souza (Malba Tahan) em diversas obras aborda a temática de forma lúdica, mas sem perder o viés histórico.

Andrade (2021), Almeida (2002), bem como Kahn (2007) discutem que as primeiras ideias a respeito de números figurados de terceira dimensão, ou simplesmente números poliedrais, podem ser encontradas no capítulo XIII da obra intitulada Introduction to arithmetic (Introdução à Aritmética), de Nicômaco de Gerasa (60-120 d.C.), filósofo neopitagórico. Introduction to arithmetic é um trabalho de grande influência, um tratado que lida com a Teoria dos números e aborda as dimensões de um número figurado. Tal obra de Nicômano de Gerasa foi traduzida por Boécio (Anicius Manlius Torquatus Severinus Boethius - $\underline{480}-\underline{524}$ (ou 525)) e apresentada em seu tratado sobre a Aritmética, que não só se baseou nas obras de Nicômaco

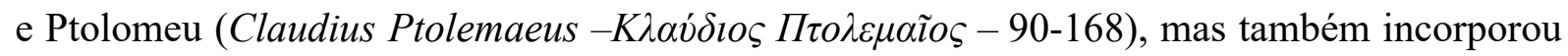

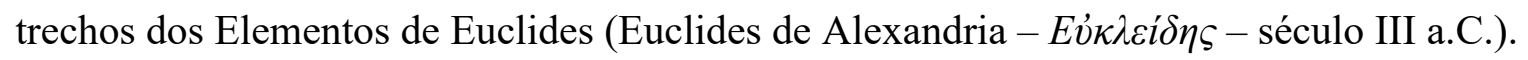

\section{Metodologia e aporte epistemológico}

Para adotarmos o processo de análise de produção de significados no viés do MCS, tomamos como referência o que fora apresentado em Silva (2012) e Silva (2003), que adotam o referido método para analisar a dinâmica da produção de significados, relativa aos temas propostos, com alunos em aulas de Álgebra Linear.

No que se refere às ideias relativas ao MCS, pautamo-nos em Lins $(2012,1999,1993)$, Silva (2012, 2003) e Lins e Giménez (1997) para apresentar algumas das noções essenciais do modelo epistemológico em questão, que nos permitiu realizar leituras de alguns resíduos de enunciação dos atores do processo, com vistas a analisar os significados produzidos pelos mesmos, relativos aos Modos de Produção de Significados ${ }^{4}$ (MPS) geométrico, aritmético e

\footnotetext{
${ }^{4}$ No espectro do MCS, MPS são ““campos semânticos idealizados’ que existem na forma de repertórios segundo os quais nos preparamos para tentar antecipar de que é que os outros estão falando ou se, o que dizem, é legítimo ou não" (LINS, 2012, p. 29, destaques do autor).
}

\section{$-5-$}

Revista de Investigação e Divulgação em Educação Matemática Juiz de Fora, v. 5, n. 1, p.1-27, Jan. - Dez., e-ISSN: 2594-4673, 2021 
algébrico, relativos à construção e generalização da sequência de números tetraédricos (números figurados piramidais triangulares), cuja gênese advém da Aritmética pitagórica. Alicerçados a partir do MCS, entendemos que tais leituras são úteis em situações de interação, “[...] como são (ou deveriam ser) todas as situações envolvendo ensino e aprendizagem, às quais vou me restringir, embora o MCS, neste aspecto, refira-se a qualquer situação de interação.” (LINS, 2012, p. 23). Essas leituras, segundo Lins (2012), apresentam-se em contraposição de uma leitura piagetiana pela falta e objetivam "[...] mapear o terreno ao mesmo tempo que trata de saber onde o outro está [...]” (p. 24).

Ao desenvolver o MCS, Romulo Campos Lins, procurava “" [...] dar conta de caracterizar o que os alunos estavam pensando quando 'erravam', mas sem recorrer à 'ideia de erro"” (LINS, 2012, p. 11, destaques do autor), para que estes passassem a se autoquestionar a respeito de suas próprias respostas, produzindo significados. Com isso, neste modelo epistemológico é proposto um tratamento àquilo que usualmente é considerado como "erro" da mesma forma que as coisas consideradas "certas", recorrendo ao conceito de conhecimento e a outras ideias presentes no MCS, na qual não há restrição a seu estudo enquanto uma teoria, mas a preocupação em se constituir como teorização adotada, pois, segundo Lins (2012, p. 11), o Modelo só existe em ação e "[...] o aspecto central de toda aprendizagem é a produção de significados." (LINS, 1999, p. 86, destaques do autor).

Desta forma, evidenciamos que significado é uma ideia central para o MCS, sendo este

[...] o conjunto de coisas que se diz a respeito de um objeto. Não o conjunto do que se poderia dizer, e, sim o que efetivamente se diz no interior de uma atividade. Produzir significado é, então, falar a respeito de um objeto. (LINS; GIMÉNEZ, 1997, p. 145146, destaques dos autores).

Por isso é fundamental que o aluno fale, expresse o que pensa a respeito do que lhe é apresentado. Ou, como fora posto pelo Prof. Romulo, "Por isto é sempre preciso ler o aluno, saber onde ele está." (LINS, 2012, p. 27). E é isso que pretendemos, ao adotarmos o processo de análise de produção de significados, como uma ferramenta epistemológica que nos permite ler o aluno, saber onde ele está, em que direção ele fala e a partir de que lugar diz o que diz.

Silva (2003) apresenta o processo de análise da produção de significado como um método que, em linhas gerais, é desenvolvido considerando: 

tríade autor-texto-leitor, com vistas ao compartilhamento de um espaço comunicativo, que é o processo de interação no qual interlocutores são compartilhados (LINS, 2012). A ideia de interlocutor adotada refere-se a "[...] uma direção na qual se fala, um ser cognitivo [...]" (LINS, 2012, p. 19);

(ii) atividade tal como proposto por Leontiev (1984, 1978, 1972), ou seja, um processo na qual os níveis de funcionamento da atividade humana dividem-se em: (a) atividade propriamente dita; (b) ação; (c) operação;

(iii) a realização de uma leitura da produção de significado dos atores envolvidos no processo. Por produção de significado entendemos como “[...] o aspecto central de toda aprendizagem - em verdade o aspecto central de toda a cognição humana.” (LINS, 1999, p. 86). Neste processo, três grandes categorias interagem - o novo, a justificação e $o$ dado - e estão presentes na produção de conhecimento. Por justificação entendemos como sendo "[...] o que garante - para o sujeito do conhecimento - que ele pode enunciar aquela crença-afirmação.” (LINS; GIMÉNEZ, 1997, p. 142, destaques dos autores).

O que emerge com força da abordagem de Davydov é que há uma diferença entre resolver problemas (particulares) e falar sobre características de uma dada situação, por mais particular que ela seja. A palavra-chave é "falar" [...] a fala da pessoa que resolve um problema tende a explicitar o "novo" e a silenciar o "dado". Dessa forma, enquanto resolvemos um problema, "falamos" as coisas que estamos tentando entender ou descobrir, mas silenciamos as coisas que tomamos como certas, como dadas. (LINS; GIMÉNEZ, 1997, p. 122, destaques dos autores).

A partir dessa colocação, evidenciamos que, diante de uma tarefa de estudo - no sentido davydoviano - o foco da atividade de resolver problemas é o novo, contudo, na tematização da lógica das operações o foco é dirigido ao dado. Diante disso, Silva (2003) nos lembra que o silêncio em relação ao dado não é total, mas sim parcial, pois

[...] ao longo da justificação, a fala vai deixando os traços do que é dado para o sujeito naquele momento. E estes traços são de suma importância para o nosso entendimento da maneira de operar desse sujeito. Porque o dado é o que nos diz onde ele [sujeito] está e a partir de que "lugar" ele está falando. Nesse processo a justificação tem o importante papel de ser o elo de ligação entre o novo e o dado. É a partir dela que ocorre o processo aonde o novo vai se transformando em dado frente a novas situações. (SILVA, 2003, p. 57, destaques do autor). 
Ainda, em relação ao processo de análise da produção de significados, Silva (2003) aponta que, ao adotá-lo, é fundamental destacar dois elementos centrais:

$\left(1^{\circ}\right)$ os objetos - “[...] coisas sobre as quais sabemos dizer algo e dizemos." (SILVA, 2003, p. 65),

[...] aquilo para que se produz significado [...] O significado de um objeto, no interior de uma atividade, não é tudo que poderia ser dito a respeito da coisa da qual se fala (nesta ou em outras atividades)." (LINS, 2012, p. 28);

$\left(2^{\circ}\right)$ os núcleos - "O núcleo de um campo semântico é constituído por estipulações locais, que são localmente, verdades absolutas, que não requerem localmente justificação.” (LINS, 2012, p. 26).

Vale ressaltar que, à luz do MCS, "Um conhecimento consiste em uma crençaafirmação (o sujeito enuncia algo em que acredita) junto com uma justificação (aquilo que o sujeito entende como the autorizando a dizer o que diz)." (LINS, 2012, p. 12). O texto Lins e Giménez (1997) destaca que, em um “[...] conhecimento produzido, a crença-afirmação corresponde ao que é novo, ao passo que a justificação corresponde ao que é dado.” (p. 144, destaques dos autores).

Justificações estabelecem um vínculo entre crenças-afirmações e núcleos, que são um conjunto de objetos já estabelecidos e em relação aos quais significados estão sendo produzidos. Um núcleo pode ser constituído por um diagrama, por um desenho, por uma balança, por um conjunto de princípios (axiomas, por exemplo), por uma situação "realista" ou ficcional. O que importa é que é em relação aos objetos do núcleo que vai ser produzido significado, seja para que texto for. (LINS; GIMÉNEZ, 1997, p. 144, destaques dos autores).

Isto posto, destacamos então que, quando nos propomos a produzir significado para o resíduo de uma dada enunciação, na perspectiva do MCS, observamos o desencadeamento de um processo de produção de significados que, segundo Silva (2003), envolve necessariamente identificar alguns elementos que denominamos de noções categorias e que são primordiais para lermos um aluno, para procurarmos entender o quê e de que lugar ele fala, para que possamos então compreender o porquê de dizer o que diz. Passemos então a apresentar essas noções.

As noções categorias do MCS que apresentaremos neste texto são: 
(1) A constituição de objetos nos permite observar tanto os novos objetos que estão sendo constituídos quanto os significados produzidos para esses objetos. (SILVA, 2012).

(2) A formação de um núcleo é o processo que envolve as estipulações locais, as operações e sua lógica: “O núcleo de um campo semântico é constituído por estipulações locais, que são, localmente, verdades absolutas, que não requerem, localmente, justificação.” (LINS, 2012, p. 26, destaques do autor).

Na observação do núcleo, numa dada atividade, podemos identificar a maneira de operar dos sujeitos bem como a lógica das operações ligadas ao processo de produção de significado para um texto. As operações são o que o sujeito faz com os objetos e a lógica é o que garante que ele pode fazer. (SILVA, 2003, p. 64).

A respeito das operações e suas respectivas lógicas, Lins e Giménez (1997) destaca que "O que é importante, aqui, é enfatizar que toda operação é realizada segundo uma lógica, e que é essencial investigar essas lógicas se queremos entender as formas de pensar de nossos alunos." (p. 114, destaques dos autores).

(3) Fazer emergir a fala na direção de interlocutores nos permite compreender de que lugar o enunciador de um resíduo de enunciação está falando, pois, no MCS, um interlocutor é uma direção na qual se fala e

Quando falo na direção de um interlocutor é porque acredito que este interlocutor diria o que estou dizendo e aceitaria/adotaria a justificação que me autoriza a dizer o que estou dizendo. O interlocutor é um ser cognitivo, não um ser biológico [...] Nossos interlocutores marcam, em última instância, o que chamei, em 1987, de horizonte cultural, os limites do possível, já que eles são as marcas da legitimidade, do que pode ser dito.

Interlocutores são legitimidades. $\mathrm{O}$ que internalizamos, nos processos de humanização e do que se costuma chamar de desenvolvimento intelectual, são interlocutores, são legitimidades. (LINS, 2012, p. 19-20, destaques do autor).

(4) As legitimidades, isto é, "[...] o que é legítimo ou não dizer de uma atividade." (SILVA 2003, p. 65; SILVA, 2012, p. 81), “[...] aplicam-se ou não a modos de produção de significado [...]” (LINS, 2012, p. 21). Por isso, “Internalizar interlocutores, legitimidades, é o que torna possível a produção de conhecimento e de significado, torna possível antecipar uma legitimidade do que digo." (LINS, 2012, p. 20). Mais ainda: “O silêncio, [...] a reprovação 
escolar [...] são algumas formas de se negar a legitimidade a dados modos de produção de significado" (LINS, 2012, p. 22).

Com isso, ao elencarmos esse conjunto de noções afirmamos que as mesmas serão consideradas, explícita ou implicitamente, na análise do processo que denominamos de produção de significados.

Vale destacar que, a partir de nossas análises, não temos a pretensão de dizer que "passaremos um pente-fino" nos discursos fazendo emergir "todos" os significados existentes nos resíduos de enunciação analisados. Isso porque, como afirmara o Prof. Romulo em entrevista,

Toda produção de significados envolve perda de significados. Num sentido muito preciso: para produzir significados é sempre em relação a um núcleo. Mas toda vez que você estabelece um núcleo, você deixa coisas de fora. No sentido de que tem coisas para as quais você não pode produzir significados. A produção de significados estabelece um recorte, uma categorização e, portanto, ela deixa coisas de fora. (SILVA, 2003, p. 64).

Daí, evidenciamos que, ao analisarmos uma produção de significados estabelecemos um recorte e, para tal, tomamos como premissa a seguinte estipulação local: Quem produz significado não é o autor do texto (enunciação), mas o leitor e, portanto, “[...] a produção de significado se dá sempre no interior de atividades.” (LINS, 1999, p. 88).

\section{O processo em ação}

A partir do Gepemem desenvolvemos um projeto de pesquisa - "Pitágoras: em (e além do) teorema" - e, em sua dinâmica, reunimo-nos periodicamente para realizar estudos e produzir conhecimento focando o desenvolvimento de ações, práticas educativas e tarefas de ensino.

Antecedente a este momento, relativo ao estudo dos números tetraédricos, realizamos vários estudos, ações e produções com os números figurados planos (ANDRADE, 2021; BONATTO, 2019; CHAVES, 2020; CHAVES; BONATTO; DUTRA; FERNANDES; ANDRADE, 2019; DUTRA, 2020; DUTRA; CHAVES, 2020). Para determinarmos o termo 
geral de cada sequência de números figurados planos (triangular ${ }^{5}$, quadrado, pentagonal, hexagonal e $n$-gonal qualquer) seguimos uma dinâmica que denominamos de trânsito entre modos de produção de significado (MPS); isto é, partimos da representação geométrica com distribuição de pontos formando os respectivos polígonos representativos (MPS geométrico); em seguida, com uso de uma tabela - similar à que apresentamos adiante (tabela 1) relacionamos a ordem com o número de total de pontos que representam o número figurado (MPS aritmético); para depois, utilizando técnica de recorrência ou recursividade, para a identificação da lógica das operações, determinarmos a representação geral (MPS algébrico) do número figurado $\left(f_{\alpha}(n)\right)$, sendo $\alpha$ o número de lados do polígono e $n$ a ordem que ocupa na respectiva sequência numérica ${ }^{6}$ (DEZA; DEZA, 2012).

Ressaltamos que toda sequência de números figurados (planos, espaciais, multidimensionais) inicia-se pelo termo $\mathrm{um}$, pois, como apresentamos em nossas ancoragens históricas, para os pitagóricos, os primeiros a estudarem o comportamento dos números figurados, o um era o princípio criador e por isso constitui-se sempre como o primeiro termo de cada sequência de números figurados.

Para se construir os respectivos termos gerais dos figurados planos não houve problemas para os atores do processo (integrantes do projeto: licenciandos em Matemática, na época mestrandos e professores da Educação Básica), tanto que não foi necessário recorrer às fórmulas já conhecidas ao longo da História. Para esses atores, os figurados planos constituíam-se como dado. Analisar os MPS supracitados foi suficiente para se constituir os respectivos termos gerais como novos objetos, a partir da recursividade e da metodologia que adotamos.

Assim, iniciamos o estudo dos números tridimensionais, começando pelos números tetraédricos ou piramidais triangulares (figura 1). Um número piramidal triangular, é um número figurado que pode ser representado por um tetraedro.

\footnotetext{
5 "O caso mais conhecido é dos números triangulares $(1,1+2,1+2+3, \ldots)$ associados ao jovem Gauss, de quem se diz que, com 11 anos, soube calcular o triângulo de 100 linhas" (LINS; GIMÉNEZ, 1997, p. 65).

${ }^{6}$ Assim, por exemplo, $f_{3}(4)=10$, significa que 10 é o quarto termo da sequência de números figurados triangulares.
} 
Figura 1 - Representação de números tetraédricos usando hastes e esferas imantadas

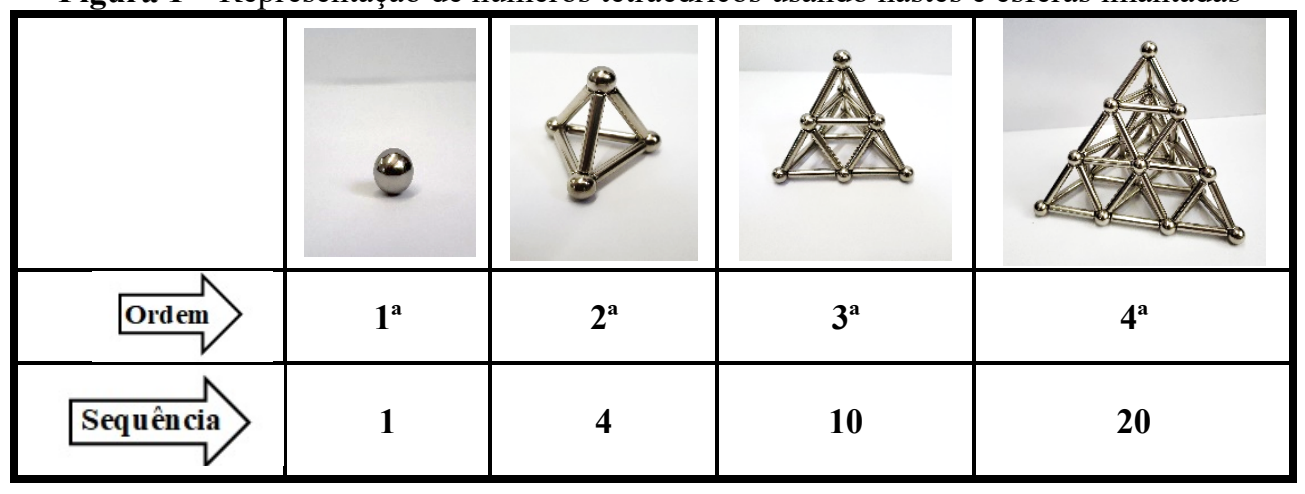

Fonte: construído pelos próprios autores.

Destacamos que a prática que deu origem a este artigo transformou-se em um curso de formação continuada, na modalidade de extensão (Edital 007/2020, Direx - campus Vitória, Ifes) de 48h, destinado a professores da Educação Básica e a licenciandos em Matemática. Com o propósito de minimizar custos e viabilizar o desenvolvimento dessa prática em sala de aula, em turma de Ensino Médio, abandonamos as esferas e hastes imantadas (figura 1) e passamos a utilizar balas do tipo jujuba (ou gometes) e palitos de dente (figura 2). Neste artigo não trataremos dos significados produzidos pelos participantes deste curso, mas das práticas que foram a gênese para a elaboração do referido curso de formação.

Figura 2 - Representação de números tetraédricos usando jujubas e palitos

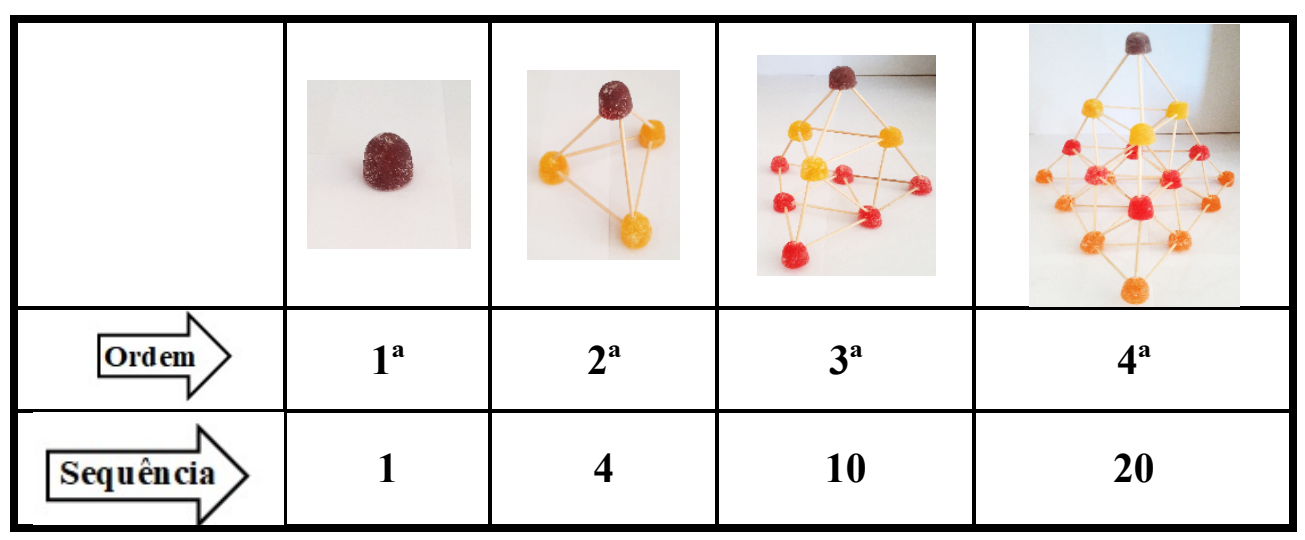

Fonte: construído pelos próprios autores. 
Seguindo a mesma dinâmica, os atores lançaram-se a analisar os objetos constituintes na formação de números tetraédricos, considerando os MPS geométrico, aritmético e algébrico.

Figura 3 - MDP utilizado para confeccionar números tetraédricos

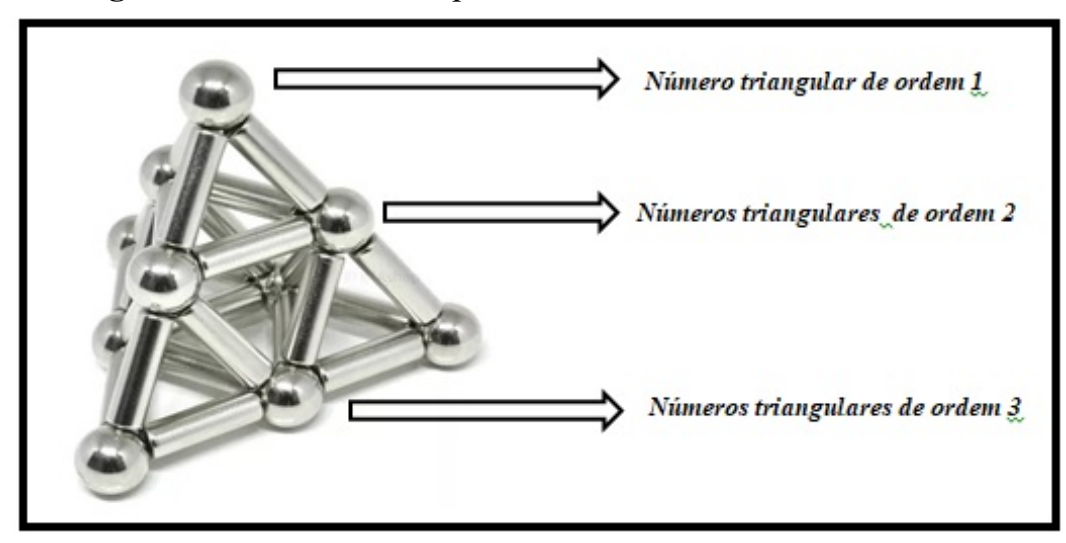

Fonte: construído pelos próprios autores.

Para tal, os mesmos representaram geometricamente cada número (usando esferas de aço e hastes imantadas [figura 3]), preencheram a tabela 1 (a seguir) e, tal como fizemos com os figurados planos, destacaram a representação gnomônica (quantidade de pontos ou esferas que acrescentamos para formar o termo de ordem subsequente, que na tabela a seguir está grafada em tom mostarda), que pode ser observada na coluna central da tabela 1 .

O uso dos materiais adotados (jujubas e palitos) (figura 2), com a metodologia de separação das bases - ou seções transversais - por cores, possibilitou aos participantes produzirem significados de que essas secções, bem como o vértice (figura 3), formavam uma sequência de números triangulares ( o dado) e, portanto, a distribuição gnomônica se dá a partir da constituição de números triangulares (o novo). 
Tabela 1 - Para análise dos MPS aritmético e algébrico

\begin{tabular}{c|c|c}
\hline Ordem & Soma das parcelas & $\begin{array}{c}\text { Total- Número piramidal } \\
\text { triangular } S_{3}^{3}(\boldsymbol{n})\end{array}$ \\
\hline 1 & 1 & 1 \\
\hline 2 & $1+3$ & 4 \\
\hline 3 & $1+3+6$ & $\mathbf{1 0}$ \\
\hline 4 & $1+3+6+10$ & 20 \\
\hline 5 & $1+3+6+10+15$ & 35 \\
\hline 6 & $1+3+6+10+15+21$ & $\mathbf{5 6}$ \\
\hline 7 & $1+3+6+10+15+21+28$ & $\ldots$ \\
\hline$\ldots$ & $\ldots$ & $S_{3}^{3}(\boldsymbol{n})$ \\
\hline$n$ & $1+3+6+10+15+21+28+\ldots+\frac{n \cdot(n+1)}{2}$ & 84 \\
\hline
\end{tabular}

Fonte: construído pelos próprios autores.

A nomenclatura $S_{\beta}^{\alpha}(n)$ trouxemos de (DEZA; DEZA, 2012) para o tema de números figurados tridimensionais, na qual $\alpha$ refere-se às faces (triangulares), $n$ refere-se à ordem e $\beta$ às bases (triangulares) ${ }^{7}$. Portanto, se estivéssemos trabalhando com números piramidais de base quadrada, por exemplo, a nomenclatura adotada seria $S_{4}^{3}(n)$.

Voltando à tabela 1 , observamos que as sete primeiras linhas foram preenchidas sem que os atores apresentassem algum limite epistemológico. O mesmo verificamos em relação à última linha, inclusive para escrever o termo geral $\left(f_{3}(n)=\frac{n \cdot(n+1)}{2}\right)$ da representação gnomônica, tanto que inicialmente preencheram a terceira coluna apenas até a sétima linha. Vejamos uma fala do ator FN7, relativa à questão:

\footnotetext{
${ }^{7}$ Por exemplo, $S_{3}^{3}(4)=20$ ( $4^{\mathrm{a}}$ linha da tabela 1$)$ indica que 20 é o número tetraédrico de $4^{\mathrm{a}}$ ordem.
} 
FN7 - Professor, quando formamos um novo número tetraédrico a quantidade de bolas que acrescentamos é um número triangular de mesma ordem [fala apontando e circulando cada última parcela, linha por linha, da coluna central da tabela 1 e com sólido metálico (tetraedro - figura 3) em mãos, aponta o vértice, a base média e a base maior, como estivesse seccionando paralela à base a cada número triangular identificado]; então, na ordem $\underline{n}$ o gnomon é $f_{3}(n)=$ $\frac{n \cdot(n+1)}{2}$ [fala e escreve a fórmula na lousa terminando de preencher a última linha da $2^{\mathrm{a}}$ coluna da tabela 1$]$.

A partir do resíduo de enunciação supracitado, identificamos que os objetos constituídos por FN7 foram: sequência de números triangulares; representação gnomônica de termos de uma sequência de números figurados; representação algébrica de um número triangular $\left(f_{3}(n)=\frac{n \cdot(n+1)}{2}\right)$ etc.

Identificamos como estipulações locais, por exemplo: o que é um gnomon; a possibilidade de se obter um número tetraédrico analisando sua distribuição gnomônica; a possibilidade de utilizar a técnica de recorrência (ou recursividade) para constituir o termo geral de um número tetraédrico.

Vale ressaltar que estes mesmo atores, em reuniões pretéritas, consideravam como situação genérica ${ }^{8}$ - como posto em Lins e Giménez (1997) - que os números figurados obedecem a uma distribuição gnomônica específica em relação à forma $\mathrm{e}$, por isso, afirmamos que a possibilidade de se obter um número tetraédrico analisando sua distribuição gnomônica constituiu-se como uma estipulação local.

Observemos que, pelo exposto por FN7, o preenchimento da tabela 1 constitui-se como a formação de um núcleo que, como apresentamos, é um processo que envolve as estipulações locais, as operações e sua lógica.

\footnotetext{
8 “[...] a situação 'genérica' emerge quando tratamos diretamente daquilo que é geral numa situação, sem a intermediação dos casos particulares. Isso não quer dizer, é claro, que a situação genérica se constitua independentemente de qualquer caso particular (embora isso não seja nada improvável ou impossível!), e, sim, que, no interior da atividade, a atenção é diretamente dirigida ao que é geral, e não ao processo de 'generalização'." (LINS; GIMÉNEZ, 1997, p. 114, destaques dos autores).
} 
Ao destacar em tom mostarda a sequência de números triangulares, o conceito de número figurado triangular é a categoria que designamos como o dado, mas a última coluna (grafada em roxo na tabela antecedente) é o que fora designado como o novo. Da mesma forma, para esse ator, identificar que a distribuição gnomônica ocorre a partir de distribuição de números triangulares constitui-se como o novo, assim como o preencher a última coluna da tabela 1 .

A partir do resíduo de enunciação supracitado, observamos que o ator FN7 (pela sua fala e seus gestos em relação à tabela e ao sólido geométrico) produziu significados aritméticos e geométricos na constituição dos objetos.

É possível também observar que este ator, mesmo não conseguindo identificar uma recorrência, para o núcleo "tabela 1" - pelo menos naquele momento -, produziu significados (geométrico, aritmético e algébrico), logo, conhecimento, pois, como já apresentado, “[...] significado é o conjunto de coisas que se diz a respeito de um objeto. Não o conjunto do que se poderia dizer, e, sim, o que efetivamente se diz no interior de uma atividade." (LINS; GIMÉNEZ, 1997, p. 145, destaques dos autores). Pelo exposto, podemos enunciar que, naquele instante, aparentemente, FN7 operava em um campo semântico que possui em seu núcleo (“tabela 1") uma análise das colunas e linhas, constituindo novos objetos (como, por exemplo, a sequência de números tetraédricos na última coluna) e que, a partir desta análise, ele transitou entre os MPS geométrico, aritmético e, até certo momento, algébrico. A ressalva deve-se ao fato de que, como o objeto $f_{3}(n)=\frac{n \cdot(n+1)}{2}$ fora tomado como uma estipulação local, podemos dizer isso, mesmo sem ter aplicado a técnica de recorrência ou recursividade para obter o termo geral $S_{3}^{3}(n)$.

Observemos também que, na sua lógica de operações, é possível obter um número tetraédrico a partir da soma de números triangulares (da mesma ordem, com os de ordens antecedentes) e a justificação é apresentada tanto pelo destaque - o tom mostarda - apresentado na tabela 1 (produção de significado aritmético) quanto pela utilização do tetraedro metálico, ao apontar com o dedo indicador cada número triangular nas camadas ou secções horizontais formadas (figuras 2 e 3) (produção de significado geométrico).

O senso comum nos leva ao entendimento de que FN7 procura constituir o diálogo com o ator Professor como interlocutor, mas lembramos que, para o MCS, “O interlocutor é uma 
direção na qual se fala [...] é um ser cognitivo, não um ser biológico.” (LINS, 2012, p. 19, destaques do autor). Nossos interlocutores "[...] são a marca da legitimidade, do que pode ser dito.” (LINS, 2012, p. 19). Por esse espectro, podemos dizer que, tanto o sólido metálico que tomou em suas mãos (figura 3), quanto a sequência de números triangulares foram seus interlocutores pelo mesmo achar ser legítimo toma-los, visto que identificou padrões (geométrico e aritmético) que apontam para a presença dos mesmos; e mais, é possível que este ator não tenha conseguido, por recorrência (ou recursividade), determinar o termo geral dos tetraédricos por não ter constituído novos interlocutores. Isto que apresentamos pode ser elucidado com os resíduos de enunciação a seguir.

SPRC - É, mas por recorrência não conseguimos chegar ao termo geral. No livro amarelo [(DEZA; DEZA, 2012, p. 88)] tem a fórmula, mas não conseguimos chegar nela.

Professor - Então escreva a fórmula na lousa.

SPRC $-S_{3}^{3}(n)=\frac{n \cdot(n+1) \cdot(n+2)}{6}$ [consultando Deza e Deza $(2012$, p. 88)].

Professor - O que te vem à mente quando olhas para essa fórmula?

SPRC - Dá pra ver que aí aparece o termo geral de um número triangular.

Professor - Onde?

SPRC - Aqui, oh! [reproduzimos as cores utilizadas pelo ator SPRC ao grafar na lousa]

$$
\frac{n \cdot(n+1) \cdot(n+2)}{6}=\frac{(n+2)}{3} \cdot \frac{n \cdot(n+1)}{2}\left[\text { destacando o termo geral } f_{3}(n)\right. \text { ] }
$$

Professor - Bom, os livros de História da Matemática nos dizem que esta fórmula era conhecida por Arquimedes e que ele a usava para determinar volumes de pirâmides. Sabemos que o volume de um tetraedro é um terço da área da base pela altura, mas ainda não está saindo, porque o 3 do denominador aparece ... Não, não ... esqueçam meus devaneios.

Os atores (SPRC e Professor) desse diálogo (autor é quem fala, texto é o que é dito e leitor é quem ouve), ao escreverem e reorganizarem a fórmula conhecida ao longo da História, buscam constituir novos interlocutores, portanto, instaurar novas legitimidades e nesse 
processo, buscam compartilhar um mesmo espaço comunicativo. Mesmo a última fala de Professor acena à tentativa de constituir novos interlocutores (cálculo de volumes de tetraedro). Essas novas tentativas evidenciam-se mais ao analisarmos os resíduos de enunciação dos diálogos a seguir.

$$
\begin{aligned}
& \text { Ruivo - E esse } \frac{(n+2)}{3} \text { quer dizer o quê? } \\
& \text { SPRC - É isso que a gente tem que descobrir! }
\end{aligned}
$$

Professor - [olhando fixamente já há alguns instantes para a tabela e para a fórmula reescrita pelo ator SPRC] Será que se escrevermos de outra forma fica mais claro? [dirige-se à lousa e grafa]

$$
\frac{(n+2) \cdot(n+1) \cdot n}{3 \cdot 2 \cdot 1}
$$

Ruivo - Por que você colocou esse 1 no denominador, se ele é elemento neutro da multiplicação?

Professor - Para ver se nos aponta para alguma direção e porque 3, 2 e 1 são os divisores de 6. Por exemplo, dá pra ver que tanto no numerador quanto no denominador temos o produto de um número com seu sucessor e seu antecessor?

SPRC - Dá, mas e daí?

Professor - Isso está me cheirando a uma simplificação de fatoriais. Vamos escrever um triângulo de Pascal [TP] para ver no que dá? [O ator SPRC o faz e em seguida Professor estende a tabela reescrevendo esses números do TP como números binomiais (tabela 2)].

Vejamos que a "tabela 1" - que antes fora constituída como um núcleo - a partir dos resíduos de enunciação (da caixa de diálogos antecedente) passa a configurar como um dado e o novo advém do objeto

$$
S_{3}^{3}(n)=\frac{n \cdot(n+1) \cdot(n+2)}{6} .
$$

É sobre esse objeto que os atores do processo buscam produzir significado. Observemos que a partir deste objeto outros objetos são constituídos. São eles:

$$
\frac{n \cdot(n+1) \cdot(n+2)}{6}=\frac{(n+2)}{3} \cdot \frac{n \cdot(n+1)}{2} \quad \text { e } \frac{(n+2) \cdot(n+1) \cdot n}{3 \cdot 2 \cdot 1}
$$


Porém, na formulação do processo de análise de produção de significados uma noção essencial é a lógica das operações, que diz respeito ao "[...] conjunto de estipulações, dentro de um núcleo, que se referem diretamente ao que pode ser feito com os objetos que estamos constituindo pela produção de significados.” (LINS; GIMÉNEZ, 1997, p. 145).

Então, a lógica das operações que envolvia esses objetos, a que nos referimos anteriormente, permitiu que os atores passassem a operar a partir de um núcleo no qual o triângulo de Pascal (TP) passou a ser uma estipulação local. A justificação para tal advém da observação de Professor ao identificar uma possível existência de simplificações de fatoriais. Mesmo que operando no campo da "intuição", essa se configura como uma legitimidade.

Tabela 2 - Triângulo de Pascal (TP) e distribuição por números binomiais

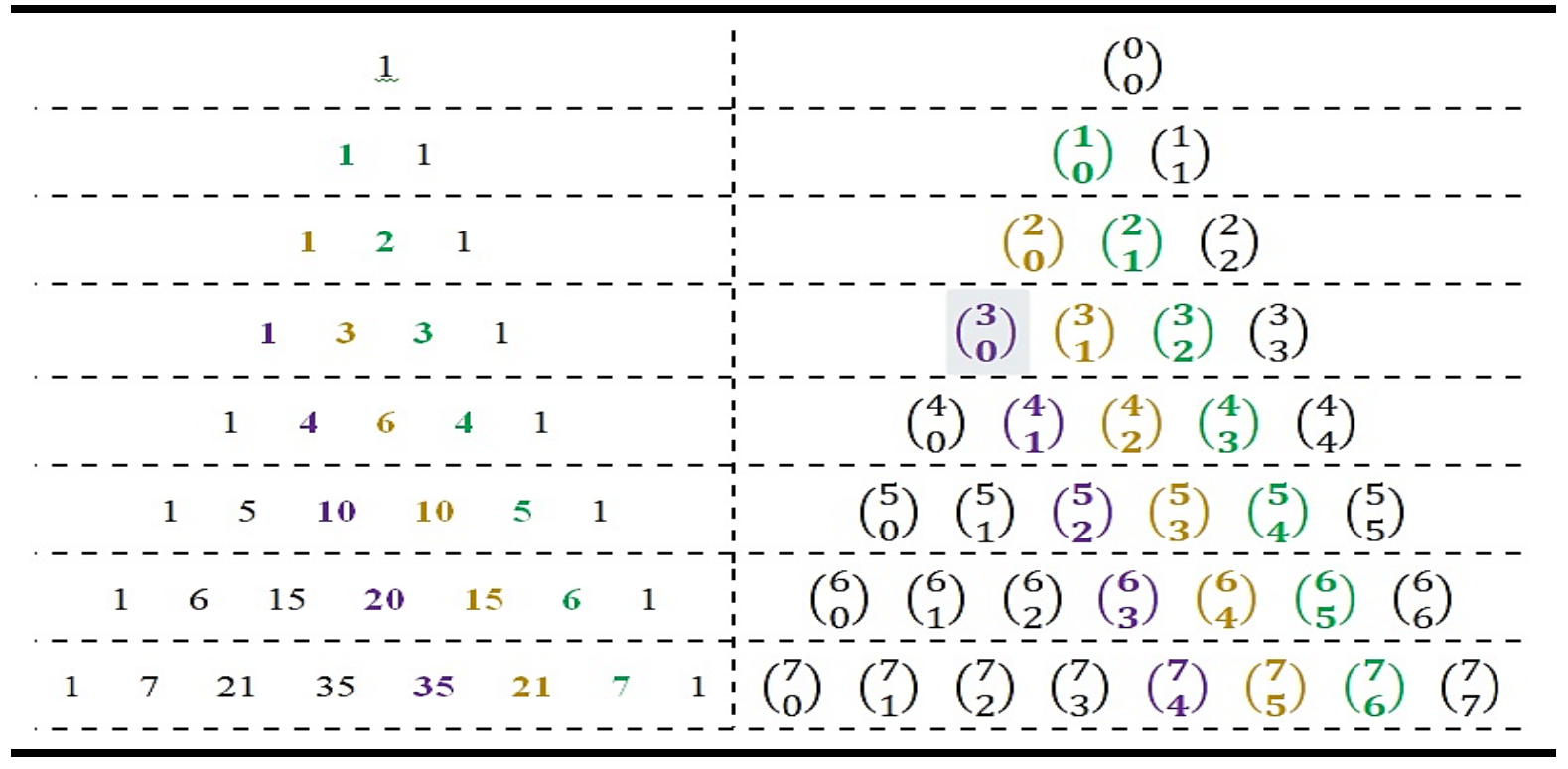

Fonte: construído pelos próprios autores.

Lembremo-nos que o ator Professor apresentou a crença-afirmação de que estes objetos poderiam se relacionar com os números do TP, mas como apresentamos anteriormente, as “[...] justificações estabelecem um vínculo entre as crenças-afirmações e núcleos, que são um conjunto de objetos já estabelecidos e em relação aos quais significados estão sendo produzidos.” (LINS; GIMÉNEZ, 1997, p. 144).

A fala de FN7, a seguir, configura-se como uma justificação para o núcleo que denominamos de "distribuição binomial", cujos objetos são os números binomiais, o próprio 
TP e as diagonais destacadas com cores diferentes por esse ator. Como afirmamos, a "tabela 1", deixou de constituir-se como objeto, da mesma forma que o sólido geométrico de metal (o tetraedro utilizado por FN7), o que nos direciona ao que Silva (2003) nos reporta: (a) que, "[...] se a atividade muda, a produção de significados também pode mudar.” (p. 52); (b) um núcleo “[...] não se refere a algo estático, um conjunto de coisas, e sim, a um processo que se constitui no interior de atividades e dissipa ao final delas. Em uma outra atividade, novo núcleo se constitui e esse é o processo.” (p. 64).

FN7 - [dirige-se à lousa e destaca os números do TP (1 $1^{\mathrm{a}}$ coluna da tabela 2$\left.)\right]$ Professor, viu que a segunda diagonal [da direita à esquerda grafada em verde na tabela 2] é a ordem, a terceira diagonal [grafada em tom mostarda] são os números triangulares da mesma ordem e na quarta diagonal [grafadas em roxo] é a sequência de números tetraédricos de ordem n $\underline{\text { ? }}$ ?

Professor - [destacando na lousa os números binomiais para facilitar a leitura] Rapaz, eu acho que ai vai dar caldo, heim!

Ruivo - Está surgindo mais de um padrão nessas diagonais dos binomiais.

Professor - Então vá à lousa e escreva o que estás enxergando.

O texto Lins e Giménez (1997) nos afirma que “[...] o que importa é que é em relação aos objetos do núcleo que vai ser produzido significado, seja para que texto for [...]" (p. 144). Isso pode ser observado não apenas pelas falas dos atores, mas pelo que escreveram na lousa, como, por exemplo, quando o ator Ruivo vai à lousa e cria uma nova tabela (figura 4) e identifica os seguintes padrões [preenchendo até a sétima coluna]. 
Figura 4 - Padrões identificados a partir do TP

\begin{tabular}{|c|c|c|c|c|c|c|c|c|c|}
\hline $\begin{array}{l}\text { Ordem } \\
\qquad \begin{array}{l}n\end{array}\end{array}$ & $\begin{array}{l}\left(\begin{array}{l}1 \\
0\end{array}\right) \\
1\end{array}$ & $\begin{array}{l}\left(\begin{array}{l}2 \\
1\end{array}\right) \\
2\end{array}$ & $\begin{array}{l}\left(\begin{array}{l}3 \\
2\end{array}\right) \\
3\end{array}$ & $\begin{array}{l}\left(\begin{array}{l}4 \\
3\end{array}\right) \\
4\end{array}$ & $\begin{array}{l}\left(\begin{array}{l}5 \\
4\end{array}\right) \\
5\end{array}$ & $\begin{array}{l}\left(\begin{array}{l}6 \\
5\end{array}\right) \\
6\end{array}$ & $\begin{array}{l}\left(\begin{array}{l}7 \\
6\end{array}\right) \\
7\end{array}$ & $\cdots$ & $\begin{array}{c}\left(\begin{array}{c}n \\
n-1\end{array}\right) \\
n\end{array}$ \\
\hline $\begin{array}{l}\text { Gnômons } \\
\frac{n \cdot(n+1)}{2}\end{array}$ & $\left(\begin{array}{l}2 \\
0\end{array}\right)$ & $\left(\begin{array}{l}3 \\
1\end{array}\right)$ & $\left(\begin{array}{l}4 \\
2\end{array}\right)$ & $\left(\begin{array}{l}5 \\
3\end{array}\right)$ & $\left(\begin{array}{l}6 \\
4\end{array}\right)$ & $\begin{array}{l}\left(\begin{array}{l}7 \\
5\end{array}\right) \\
21\end{array}$ & $\begin{array}{l}\left(\begin{array}{l}8 \\
6\end{array}\right) \\
28\end{array}$ & $\cdots$ & $\begin{array}{l}\left(\begin{array}{l}n+1 \\
n-1\end{array}\right) \\
\frac{n \cdot(n+1)}{2}\end{array}$ \\
\hline Piramidal & $\left(\begin{array}{l}3 \\
0\end{array}\right)$ & $\left(\begin{array}{l}4 \\
1\end{array}\right)$ & $\left(\begin{array}{l}5 \\
2\end{array}\right)$ & $\left(\begin{array}{l}6 \\
3\end{array}\right)$ & $\left(\begin{array}{l}7 \\
4\end{array}\right)$ & $\left(\begin{array}{l}8 \\
5\end{array}\right)$ & $\left(\begin{array}{l}9 \\
6\end{array}\right)$ & $\cdots$ & 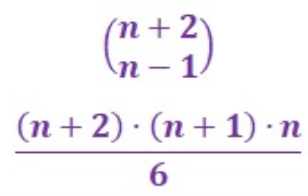 \\
\hline
\end{tabular}

Fonte: construído pelos próprios autores.

Com essa ação de Ruivo podemos dizer que o mesmo produziu significado aritmético para o objeto que criou - preenchimento da tabela (figura 4) - mas foi o ator SPRC que produziu significado algébrico para esse mesmo objeto, ao completar a última coluna da tabela em questão. O que não significa que tenhamos condições de afirmar que Ruivo não produziu significados algébricos, pois, afirmar isso seria realizar uma leitura piagetiana pela falta (o que faltou a Ruivo para generalizar os binomiais na última coluna).

Outra ideia pertinente ao MCS é a noção de limite epistemológico, que “[...] é a impossibilidade do sujeito produzir significado para o resíduo de enunciação numa certa direção devido à sua maneira de operar." (SILVA, 2012, p. 88). Isso podemos identificar no resíduo de enunciação de Professor, quando afirmou "Sabemos que o volume de um tetraedro é um terço da área da base pela altura, mas ainda não está saindo, porque o 3 do denominador aparece ... Não, não ... esqueçam meus devaneios.". Tal evidência fica mais presente quando constatamos que "[...] estar frente a um limite epistemológico pode levar ao ponto de paralisar o processo de produção de significados desses sujeitos." (SILVA, 2012, p. 88).

O ator SPRC, ao se deparar com o objeto, sequência de números tetraédricos,

$$
1,4,10,20,35,56,84, \ldots, S_{3}^{3}(n)
$$

constituído por ele e por FN7, e ao enunciar que "por recorrência não conseguimos chegar ao termo geral" evidencia-se a impossibilidade de produzir significado para o resíduo de

\section{-21-}

Revista de Investigação e Divulgação em Educação Matemática Juiz de Fora, v. 5, n. 1, p.1-27, Jan. - Dez., e-ISSN: 2594-4673, 2021

do: $10.34019 / 2594-4673$. 
enunciação relativo ao objeto supracitado, na direção da generalização, pois sua maneira de operar - por recorrência - advém da maneira como trabalhamos com os números figurados planos, ou seja, queríamos imputar a mesma lógica das operações entre figurados planos às operações com números tetraédricos, possivelmente por tomarmos como estipulação local a situação genérica de que os números figurados obedecem a uma distribuição gnomônica específica em relação à forma e, por isso, tentávamos imputar a mesma lógica de operações imputada aos figurados planos. Daí, podemos afirmar que essa impossibilidade constituiu-se, naquele momento, como um limite epistemológico.

Professor - E agora, podemos generalizar então?

SPRC - Sim! Pra ordem nós temos essa estrutura $\left(\begin{array}{c}n \\ n-1\end{array}\right)$. Pros gnomons fica

$\left(\begin{array}{l}n+1 \\ n-1\end{array}\right)$. E pros tetraédricos fica $\left(\begin{array}{l}n+2 \\ n-1\end{array}\right)$.

Professor - Então, como chegaremos ao termo geral?

SPRC - Ah, desenvolvendo algebricamente... Assim, ó! [dirige-se à lousa e desenvolve algebricamente da maneira a seguir]

$S_{3}^{3}(n)=\left(\begin{array}{l}n+2 \\ n-1\end{array}\right)=\frac{(n+2) \cdot(n+1) \cdot n \cdot(n-1) !}{(n-1) ! \cdot(\not+2-\not 1+1) !}=\frac{(n+2) \cdot(n+1) \cdot n}{3 !}=\frac{(n+2) \cdot(n+1) \cdot n}{6}$

Observemos que o TP (tabela 2), com suas respectivas representações - distribuição binomial e respectivos resultados destas distribuições - constituem-se como objetos para os atores Professor, FN7 e SPRC. Após FN7 destacar as respectivas diagonais e Professor repetir esses destaques para as distribuições binomiais, o ator Ruivo também passa a constituir essa tabela como objeto e isso fica explícito ao enunciar que identifica o surgimento de padrões que o leva a grafar o que representamos como figura 4. A esse respeito convém elucidar que “[...] o que pode ser feito com esse objeto depende exatamente daquela lógica das operações com todo e partes." (LINS; GIMÉNEZ, 1997, p. 145). Foi o que ocorreu quando SPRC conclui a figura 3, preenchendo a última coluna e, assim, produzindo significado algébrico para aqueles objetos. 
É possível dizermos que o ator Ruivo, naquele momento, operava em um campo semântico constituído considerando um núcleo de "padrão numérico", mas não podemos afirmar que o mesmo operava em um campo semântico constituído com base na técnica de recorrência, pois ele preencheu as sete primeiras colunas da figura 4. Por outro lado, com a apresentação da generalização constatada pelo ator SPRC, é possível declararmos que o mesmo, naquele momento, operava em um campo semântico constituído com base em um núcleo cuja estipulação local era o uso da recursividade, por operar com a noção algébrica da sequência de binomiais a partir das linhas da tabela (figura 4).

A lógica para escrever o termo geral da $1^{\mathrm{a}}$ linha dessa operação e grafar, por exemplo, o termo geral $\left(\begin{array}{c}n \\ n-1\end{array}\right)$, consiste em identificar que, no binomial, o numerador relaciona-se à ordem e o desnominador é o antecessor dessa ordem, da mesma forma que, em relação à terceira linha, o termo geral $\left(\begin{array}{l}n+2 \\ n-1\end{array}\right)$ que representa um número tetraédrico, está em identificar que, neste binomial, o numerador $(n+2)$ indica duas casas após a ordem e o denominador $(n-1)$ é o antecessor da ordem.

Ainda em relação ao objeto "tabela 2" é possível destacarmos que tanto para Ruivo quanto para SPRC a segunda coluna, da distribuição binomial, passa a constituir-se como $o$ novo enquanto que a primeira coluna, dos números do TP passa a ser o dado e a justificação é apresentada por SPRC ao enunciar que usará o desenvolvimento algébrico, pois sua utilização (de recursividade) será o elo entre $o$ novo (termo geral na representação binomial $-S_{3}^{3}(n)=$ $\left(\begin{array}{l}n+2 \\ n-1\end{array}\right)$ ) e o dado $\left(S_{3}^{3}(n)=\frac{(n+2) \cdot(n+1) \cdot n}{6}\right)$, conforme discutido em Silva (2003).

A formação deste novo núcleo possibilitou que os atores do processo abandonassem os objetos anteriores - que constituíam as estipulações de "simplificação de fatorais" e o MPS geométrico, cujo o sólido metálico (figura 3) era outro objeto - e passassem a constituir novos objetos, como, por exemplo, considerando que

$$
S_{3}^{3}(n)=\left(\begin{array}{l}
n+2 \\
n-1
\end{array}\right)
$$

ou seja, passam a operar em um campo semântico com MPS aritméticos e algébricos. Observemos que, tal como apresentado em Lins (2012), o silêncio produzido pelos próprios atores do processo, a respeito do objeto "sólido metálico no formato de tetraedro" (figura 3) é 
uma forma deles mesmos negarem a legitimidade de certos MPS, no caso o geométrico. Isso não quer dizer que se constituiu o que, no MCS denominamos de impermeabilização, "[...] processo que leva os alunos a não compartilharem novos interlocutores em situação de interação face a face, diferente daqueles para o qual eles estavam voltados; de não se propor a produzir significados numa outra direção.” (SILVA, 2012, p. 79).

Lembremo-nos que o ator FN7 fez exatamente o contrário; ele migrou de MPS, constituindo a distribuição binomial como o novo e tornou o MPS geométrico como dado. Caso ele insistisse em ficar preso às mesmas técnicas que adotaram quando estudaram os números figurados, não permitindo-se a compartilhar novos interlocutores, a constituir novos objetos, então diríamos que ele tornar-se-ia impermeável a outros MPS distintos daqueles que haviam produzido. Como posto por Silva (2012), o comportamento de FN7 sugere que "[...] houve um processo sutil de transformação do que em um momento são novos objetos e em outro, se tornam estipulações.” (p. 83).

\section{Algumas considerações}

Como apontado por Silva (2012), ao analisar a produção de significados de um indivíduo é possível, por exemplo, verificar se houve (ou não) uma mudança de direção nos significados produzidos pelo mesmo, o que pode ser positivo na resolução de um problema proposto, auxiliando assim na compreensão mais global da análise.

Tomar o MCS como um modelo epistemológico permite ao professor assumir uma direção no trato com os objetos constituídos por seus alunos, bem como cambiar esta direção para que possa retomar objetos que foram esquecidos, negligenciados ou simplesmente passaram a configurarem-se como dados, ou identificar limites epistemológicos que impeçam os alunos a produzirem significados para o objeto em foco. Isto posto, evidencia-se que além de "saber Matemática", as respectivas dinâmicas e focos do assunto tratado, o professor precisa agir como um vetor (ser cognitivo, uma direção) do processo para que possa estabelecer uma interação que permita que, alunos - que encontram-se no processo de impermeabilização - e professor passem a compartilhar um mesmo espaço comunicativo.

Não se trata de evidenciar o objeto colocando o aluno em papel secundário, como o protótipo do Homo Piagetianus, posto por Lins (1993). Ao contrário. Trata-se de identificar os 
objetos constituídos pelos atores - os cidadãos solidários que são protótipos de Homens de Vygotski (LINS, 1993) - para que possamos lê-los e sabermos de que lugar falam, porque falam e o que os fez assumirem essas enunciações, pois, como apresentado pelo MCS, o "Objeto é aquilo para que se produza significado" (LINS, 2012, p. 28). Dessa forma, entendemos que estaremos intervindo diferencialmente nos processos de ensino e de aprendizagem, desestabilizando a inércia mantenedora dos quadros vigentes do ensino de Matemática.

Vale ressaltar que a prática que deu origem a esse artigo e que transformou-se em um curso de formação continuada, na modalidade de extensão (Edital 007/2020, Direx - campus Vitória, Ifes), com duração de 48 (quarenta e oito horas), destinado a professores da Educação Básica e a licenciandos em Matemática, foi citado mas não discutido por ser objeto de uma pesquisa recém concluída (ANDRADE, 2021), de um dos atores do processo, mas intencionamos, futuramente, produzir artigos que tratem da discussão dos significados produzidos pelos participantes deste processo de formação, tomando como referência Andrade (2021).

\section{Agradecimentos}

Agradecemos aos integrantes do Projeto "Pitágoras: em (e além do) teorema" pela dedicação e parceria: Prof. Alexandre Krüger Zocolotti; Davi Magalhães Vieira; Prof. Douglas Araujo Victor; Esthefany Rabello Macedo; Ian Neto Bonfim; Prof ${ }^{a}$ Veronica Borsonelli Marcarini.

Também agradecemos aos membros do Gepemem por compartilharmos espaços comunicativos, sobretudo, no que se refere às leituras e estudos relativos ao MCS: Aline da Silva Vaz; Ana Paula Azevedo Moura; Ana Paula Rodrigues da Costa; Prof ${ }^{a}$ Bea Karla Flores Machado Teixeira; Fernanda Santolin Marques; Larissa Toniato; Prof ${ }^{\mathrm{a}}$ Ligia Arantes Sad; Prof ${ }^{\mathrm{a}}$ Mariana dos Santos Cezar; Solange Taranto de Reis; Stevão Carneiro de Sousa; Thays Xavier de Araujo.

\section{Referências}

ALMEIDA, Manoel de Campos. Platão Redimido: A Teoria dos Números Figurados na Ciência Antiga \& Moderna. Curitiba: Champagnat, 2002. (Coleção Exatas, 2). 
ANDRADE, Neves de Andrade. Significados produzidos a respeito de vieses entre triângulo de pascal, números tetraédricos e figurados triangulares em um processo de formação de professores de matemática. 2021. 127 p. Monografia de Trabalho de Conclusão de Curso (Curso de Licenciatura em Matemática) - Instituto Federal do Espírito Santo. Vitória, 2021.

BONATTO, Lucca Jeveaux Oliveira; CHAVES, Rodolfo; ZOCOLOTTI, Alexandre Krüger; DUTRA, Tiago Magno de Souza. Padrões numéricos pitagóricos: significados produzidos por professores. In: ENCONTRO NACIONAL DE EDUCAÇÃO MATEMÁTICA, 13, 2019, Cuiabá. Anais... Cuiabá: SBEM-MT, 2019.

CHAVES, Rodolfo. Algumas sequências numéricas com representações geométricas na Aritmética pitagórica: números figurados bidimensionais e tetraédricos. Projeto de curso de extensão. Edital 07/2020 - Direx. Campus Vitória. Ifes, 2020.

CHAVES, Rodolfo; BONATTO, Lucca Jeveaux Oliveira; DUTRA, Tiago Magno de Souza; FERNANDES, Bruna Moll; ANDRADE, Filyppe Neves de. Interface entre os modos de produção de significado em sequências de números figurados com uso de materiais didáticopedagógicos manipulativos reaproveitáveis. Anais ... $8^{\text {a }}$ Semana da Matemática do Ifes campus Vitória. Vitória: IFES/COMAT, 2019.

DEZA, Elena; DEZA, Michel-Marie. Figurate Numbers. Singapore: World Scientific Plublishing, 2012.

DOMINGUES, Hygino Hugueros. Fundamentos de Aritmética. 2. ed. rev. Florianópolis: editora da UFSC, 2017.

DUTRA, Tiago Magno de Souza; CHAVES, Rodolfo. Números figurados planos em formação de professores. Vitória: Edifes, 2020. (Série Guia Didático de Matemática, n. 71).

KAHN, Charles H. Os filósofos neopitagórigos. In: KAHN, Charles H. Pitágoras e os pitagóricos: uma breve história. São Paulo: Loyola, 2007. p. 125-173. (Leituras filosóficas).

LEONTIEV, Alexis Nikolaevich. Actividad, conciencia y personalidade. México: Cartago, 1984.

LEONTIEV, Alexis Nikolaevich. O desenvolvimento do psiquismo. Lisboa: Horizonte Universitário, 1978.

LEONTIEV, Alexis Nikolaevich. Atividade e Consciência. 1972. In:

$<$ https://marxists.org/portugues/leontiev/1972/mes/atividade.htm>. Acesso em: 30 nov. 2015.

LINS, Romulo Campos. O Modelo dos Campos Semânticos: estabelecimento e notas de teorizações. In: ANGELO, Claudia Laus et al (org.). Modelo dos Campos Semânticos e Educação Matemática: 20 anos de história. São Paulo: Midiograf, 2012. p.11-30. 
LINS, Romulo Campos. Por que discutir teoria do conhecimento é relevante para a Educação Matemática. In: BICUDO, Maria Aparecida Viggiani. (Org.). Pesquisa em Educação Matemática: concepções \& perspectivas. São Paulo: Editora UNESP, 1999. p .75 94 (Seminários DEBATES Unesp).

LINS, Romulo Campos. Epistemologia, História e Educação Matemática: tornando mais sólida as bases da pesquisa. Revista da Sociedade Brasileira de Educação Matemática - São Paulo, Ano 1, n. 1, set./1993, p. 75-91.

LINS, Romulo Campos; GIMÉNEZ, Joaquin. Perspectivas em aritmética e álgebra para o século XXI. 3. ed. Campinas: Papirus, 1997. (Perspectivas em Educação Matemática).

MARQUES, Sofia Cardoso. A descoberta do teorema de Pitágoras. São Paulo: Livraria da Física, 2011. (Coleção História da Matemática para professores).

NICÔMACO DE GERASA. Introduction to arithmetic. Chicago: Great Books, 1952 (Encyclopedia Britannica, v. 11).

PICKOVER, Clifford Alan. O livro da Matemática: de Pitágoras à 57ª dimensão, 250 marcos da história da matemática. Kerkdriel: Librero, 2009.

ROQUE, Tatiana. História da matemática: uma visão crítica, desfazendo mitos e lendas. 2 . reimp. Rio de Janeiro: Zahar, 2014 [2012].

SILVA, Amarildo Melchiades da. Impermeabilização no Processo de Produção de Significados para a Álgebra Linear. O Modelo dos Campos Semânticos: estabelecimento e notas de teorizações. In: ANGELO, C. L. et al (org.). Modelo dos Campos Semânticos e Educação Matemática: 20 anos de história. São Paulo: Midiograf, 2012. p. 79-90.

SILVA, Amarildo Melchiades da. Sobre a dinâmica da produção de significados para a matemática. Rio Claro. 2003. 147p. Tese (Doutorado em Educação Matemática), PPGEM, IGCE de Rio Claro, Unesp.

TAHAN, Malba. Os números governam o mundo: folclore da Matemática. Rio de Janeiro: Ediouro, 1972 [1965].

\section{HISTÓRICO}

Submetido: 02 de fevereiro de 2021.

Aprovado: 25 de maio de 2021.

Publicado: 14 de julho de 2021. 